\title{
INDICADORES PARA O MONITORAMENTO DA SUSTENTABILIDADE EM SISTEMAS URBANOS DE ABASTECIMENTO DE ÁGUA E ESGOTAMENTO SANITÁRIO
}

\author{
INDICATORS OF MONITORING SUSTAINABILITY OF THE URBAN WATER SUPPLY \\ AND SEWERAGE SYSTEMS
}

\begin{abstract}
ALINE BRANCO DE MIRANDA
Engenheira Civil pela Faculdade de Engenharia Civil de Araraquara. Mestre em Engenharia Urbana pela Universidade Federal de São Carlos (UFSCar). Doutoranda em Engenharia Civil pela Universidade Estadual de Campinas (UNICAMP). Assessora Técnica do Departamento de Gestão Ambiental do Serviço Autônomo de Água e Esgoto de Jaboticabal
\end{abstract}

\section{BERNARDO ARANTES DO NASCIMENTO TEIXEIRA}

Engenheiro Civil pela UFMG, Doutor em Hidráulica e Saneamento pela EESC/USP, Professor do Programa de Pós-Graduação em Engenharia Urbana da UFSCar

Recebido: 16/01/04 Aceito: 20/07/04

\section{RESUMO}

Uma gestão adequada dos sistemas urbanos de abastecimento e esgotamento pode reduzir uma série de impactos negativos, além de trazer resultados positivos para o ambiente, a sociedade e a economia. O conceito de sustentabilidade procura incorporar estas preocupaçōes. Para que ele possa ser efetivamente aplicado, é preciso uma mudança na percepção sobre os referidos sistemas, acompanhada pela adoção de instrumentos de monitoramento. No presente trabalho, procurou-se estabelecer princípios específicos de sustentabilidade que possam ser aplicáveis àqueles sistemas, bem como foram propostos indicadores a serem utilizados como instrumentos de monitoramento, permitindo assim, orientar políticas públicas para o setor.

PALAVRAS-CHAVE: Sustentabilidade, indicadores, sistemas urbanos de água e esgoto.

\begin{abstract}
An adequate management of urban water supply and sewerage systems can reduce several negative impacts. It can also bring positive results to the environment, society and economy. The concept of sustainability tries to incorporate these concerns. In order to be effectively applied a change is necessary in the perception of the use of water, followed by the adoption of monitoring instruments. In this work, it was attempted to establish specific principles of sustainability which can be applied to the referred systems. It was also proposed indicators to be used as monitoring instruments, allowing the orientation of public policies for this sector.
\end{abstract}

KEYWORDS: Sustainability, indicators, urban water supply and sewerage systems.

\section{INTRODUÇÃO}

A água possui características essenciais para a sobrevivência da humanidade, que por sua vez é sua principal usuária e também sua maior poluidora. O fluxo da água utilizada pelas sociedades no meio urbano, pode ser resumidamente descrito como: mover a água de onde se encontra disponível para onde seu uso seja necessário, e removê-la após a utilização, com seu retorno ao ambiente. Para fazêlo, torna-se necessária a existência de sistemas de infra-estrutura, tanto para o abastecimento (SAA), quanto para o esgotamento (SES). Ao ser manipulada por estes sistemas, a água sofre diversas modificaçôes em suas características de quali- dade, quantidade, velocidade de escoamento, entre outros, que se refletem numa diminuição de sua disponibilidade, tanto para o uso humano, quanto para os processos ecológicos. A crescente e desordenada urbanização tem agravado este quadro, comprometendo os recursos hídricos e prejudicando os sistemas públicos já implantados, que passam a operar com sobrecargas e com deficiências.

Com o surgimento e a difusão do conceito de desenvolvimento sustentável, que implica na possibilidade de que as próximas geraçôes possam satisfazer suas necessidades assim como as geraçóes atuais (CMMAD, 1991), a água passa a ser considerada um recurso esgotável e objeto de grande preocupação em termos de sua disponibilidade. Além deste aspecto ambiental, também são motivos de atenção outras dimensões da sustentabilidade associadas à água, como a social, a econômica e a política, para que se possa ter uma melhor qualidade de vida para a população. Todas estas dimensōes devem ser abordadas de forma integrada, a partir de princípios de sustentabilidade, que, portanto, precisam ser claramente estabelecidos (Teixeira e Silva, 1998). Por outro lado, para que tais princípios possam se traduzir em políticas e ações concretas, é preciso que haja instrumentos de gestão que possam detectar as tendências apresentadas pelos diferentes componentes dos sistemas urbanos, entre eles os de abastecimento de água e de esgotamento sa- 
nitário. Assim, surge a necessidade de se estabelecer indicadores de sustentabilidade, que poderão dar suporte a políticas publicas que conduzam a sistemas mais sustentáveis (Silva, 2000; Sustainable Seattle, 1998).

\section{OBJETIVO}

O objetivo geral foi a obtenção de princípios e indicadores de sustentabilidade, a serem aplicados aos sistemas urbanos de abastecimento de água e esgotamento sanitário.

\section{MÉTODOS}

Para se atingir o objetivo proposto, foram realizadas duas etapas de escolha de indicadores. Na primeira, denominada "Escolha Restrita", realizada em grupo de poucas pessoas especialistas no assunto, inicialmente, foi feita uma pesquisa na literatura especializada, relacionada à sustentabilidade e ao fluxo urbano da água. Foram, assim, identificados e sistematizados os princípios gerais de sustentabilidade que vêm sendo considerados por diferentes autores e entidades, encontrados em documentos como Agenda 21, Relatório Brundtland, entre outros. Ao mesmo tempo, foram também listados os indicadores comumente utilizados no gerenciamento dos SAA eSES, bem como alguns já voltados para a sustentabilidade na literatura internacional (Lundim, 1999).

Em seguida, os princípios gerais foram analisados tendo como referência sua aplicabilidade aos SAA e SES, dando origem a princípios específicos para tais sistemas. Após esta etapa, os indicadores previamente listados, foram associados à estes princípios específicos, gerando uma lista de indicadores para cada princípio. Com a sistematização dos critérios de escolha, estabelecidos pela literatura, foram aplicados, em uma matriz, os critérios a cada indicador, ficando definidos os que receberam maior ou menor pontuação. (Milanez, 2002; Kayano e Caldas, 2002). Como resultado, foram escolhidos 13 indicadores que obtiveram maior número de critérios atendidos.

Num segundo momento, foi realizada a "Escolha Ampliada", incorporando a participação de diferentes agentes do município de Jaboticabal / SP, relacionados ou interessados na questão do fluxo da água daquele município. Após o levantamento de diferentes indicadores pelos participantes, partindo de uma escolha associada a problemas atuais enfrentados pelos SAA e SES do município, foram aplicados critérios definidos em reuniōes com os integrantes do grupo em uma matriz, resultando também em 13 indicadores.

Como resultado final, foram definidas, para os indicadores obtidos nos dois métodos de escolha, a avaliação de tendências favoráveis ou desfavoráveis à sustentabilidade, nos referidos sistemas.

\section{CONCEITOS BÁSICOS}

As reflexões sobre a sustentabilidade têm início na década de 70 com a preocupação ambiental sobre os recursos naturais utilizados pelas pessoas. Em decorrência do aparecimento dessa questão, surgem diversas discussōes no âmbito global, envolvendo a conscientização dos diversos países.

A partir dessas discussões, o conceito de sustentabilidade é elaborado, primeiramente com a visão ecológica, e posteriormente, incluindo as diversas dimensôes que envolvem o ser humano e suas necessidades e condutas. (Cavalcanti, 1999).

No entanto, para a avaliação da sustentabilidade em um determinado local é preciso a reunião de diferentes informações que possam traduzir o grau de sustentabilidade em que se encontra.

Para tanto, os indicadores são importantes ferramentas de avaliação, desde que seja possível relacioná-los aos conceitos e princípios de sustentabilidade, sendo capazes de avaliar e monitorar as tendências de desenvolvimento sustentável, definindo metas de melhoria dos sistemas.

Os indicadores têm sido utilizados na administração, seja ela pública ou privada de vários sistemas. Existem vários indicadores para cada ramo ou segmento que se queira analisar: indicadores de desempenho, para avaliar pessoas e projetos; indicadores econômico-financeiros, para a comparação de empresas e países; indicadores sócio-econômicos, para a análise da sociedade, entre outros, resumindo uma série de informaçôes que permitirão a tomada de decisão pelo administrador. (Bossel, 1999)

Ultimamente, os indicadores vêm sendo utilizados de forma conjunta, agregando uma série de informações, buscando uma visão integrada do objeto de estudo. Muitas vezes utiliza-se a comparação entre indicadores de diversas instituiçôes, sejam empresas ou governos, de for- ma que os seus administradores obtenham uma base de comparação e saibam que áreas são mais deficientes, priorizando os seus investimentos.

Os indicadores devem propor dados de forma a possibilitar análises e avaliações da transformação do meio físico e social, buscando a elaboração e formulação de políticas e ações urbanas.

$\mathrm{Na}$ construção de um sistema de indicadores, é importante que se estabeleçam os critérios e os métodos de forma coerente com os objetivos pretendidos e também com os recursos humanos, materiais e financeiros disponíveis em um dado contexto, podendo alterar a forma de governar os sistemas e proporcionar uma melhor utilização dos recursos.

Os sistemas urbanos de água e esgoto são ligados ao conceito de sustentabilidade em todas as suas dimensōes: ambiental, política, social, etc. A avaliação da sustentabilidade é de extrema importância para promover o aumento da qualidade de vida da população, garantindo saúde, acesso aos serviços, melhorias no sistema, entre outros fatores, sendo possível a partir do monitoramento de indicadores para os sistemas urbanos de água e esgoto.

\section{RESULTADOS}

\section{Primeira etapa: escolha restrita}

\section{Princípios específicos}

Foram identificados e sistematizados a partir da literatura os seguintes princípios gerais de sustentabilidade: princípio elementar (seres humanos como foco); da paz; de soberania nas relaçóes internacionais; do uso responsável dos recursos naturais; da solidariedade intergeracional; de eqüidade; da geração de renda; da cooperação e participação; da contextualização local; da eficiência econômica; da avaliação de impactos sociais e ambientais; precautório; preventivo; compensatório; e do poluidor-pagador.

A partir da associação ou adequação destes, foram estabelecidos os princípios específicos de sustentabilidade a serem aplicados aos SAA e SES, explicitados a seguir (Miranda e Teixeira, 2002):

1 - Eqüidade (universalização dos serviços): todas as pessoas têm direito ao acesso aos serviços de abastecimento de água e esgotamento sanitário, podendo suprir suas necessidades de forma digna, garantindo a saúde pública. 
2 - Respeito às Condições Locais: as soluçôes apresentadas para os SAA e SES devem considerar e adequar-se às condiçóes locais (sociedade, economia, cultura, meio físico e biológico).

3 - Desempenho Econômico: todos os projetos e serviços dos SAA e SES devem ser elaborados e oferecidos com viabilidade econômica, considerando a melhor utilização dos recursos disponíveis, sem prejuízo dos outros princípios.

4 - Geração de Trabalho e Renda: entre as alternativas para soluçóes dos SAA e SES, deve-se dar prioridade àquelas intensivas em mão de obra, proporcionando um ambiente seguro e salubre ao trabalhador.

5 - Gestão Solidária e Participativa: as decisões aplicadas aos SAA e SES devem ser tomadas de maneira participativa, havendo cooperação, divisão de trabalho e consenso entre os agentes da sociedade e o poder público.

6 - Informação e Sensibilização: a sociedade deve ter pleno acesso à informação relativa aos SAA e SES, para que possa se conscientizar dos problemas e participar das soluçôes.

7 - Uso Responsável dos Recursos Naturais: a utilização dos recursos naturais pelos SAA e SES, tanto para fornecimento de matéria-prima quanto para o recebimento de resíduos, deve ocorrer de acordo com a sua capacidade regenerativa ou de estoque, avaliando-se os impactos e aplicando soluções que possam minimizar, prevenir e corrigir os mesmos.

8 - Prevenção, Compensação e Mitigação de Danos Causados: os custos de remediação, medidas compensatórias e de prevenção de danos gerados pelos SAA e SES precisam ser devidamente considerados, sendo assumidos pelos seus causadores.

Após a explicitação dos princípios específicos para os sistemas urbanos de água e esgoto pode-se perceber a relação dos princípios com as dimensóes de sustentabilidade, conforme proposto na Figura 1.

\section{Critérios de escolha de indicadores}

A partir da revisão bibliográfica, foi identificada uma série de critérios que podem ser considerados na definição de indicadores, entre eles: coerência com a realidade local; relevância; clareza na comunicação; pró-atividade; facilidade para definição de metas; construção participativa; monitoramento participativo; complementaridade à ação comunitária;

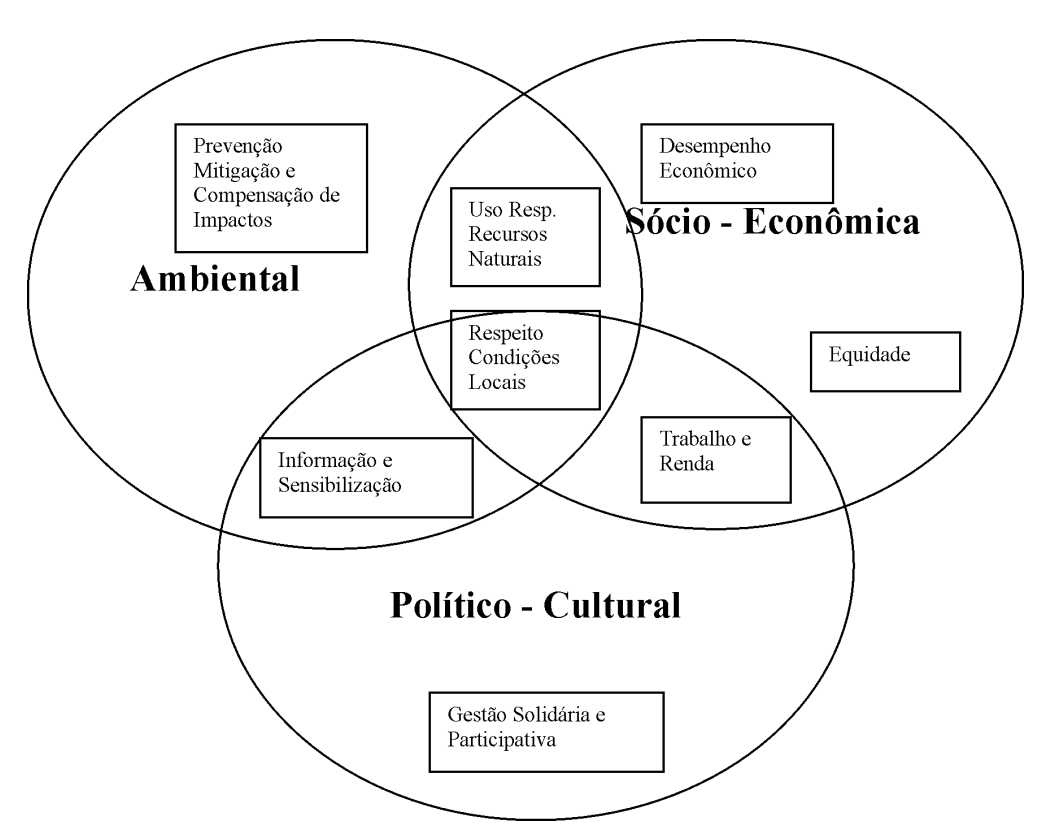

capacidade de ser quantificável; capacidade de ser qualificável; intangibilidade; tangibilidade; consistência científica; acessibilidade dos dados; confiabilidade da fonte; amplitude geográfica adequada; padronização; sensibilidade a mudanças no tempo; estabilidade no tempo; adequabilidade a mudanças da realidade; preditividade; abrangência das dimensôes; capacidade de síntese.

Tais critérios foram sistematizados, de modo a excluir os redundantes ou contraditórios, resultando na listagem a seguir, que foi utilizada na etapa de escolha dos indicadores:

- acessibilidade dos dados: facilidade ao acesso dos dados referentes ao indicador.

- clareza na comunicação: permitir uma rápida compreensão e aceitação pelos usuários.

- relevância: refletir algo básico e fundamental para descrever o fenômeno monitorado.

- amplitude geográfica: ser sensível à mudança no espaço.

- padronização: maior a possibilidade de comparar uma realidade com as demais.

- preditividade: avisar antecipadamente os problemas antes que se tornem de difícil solução.

- pró-atividade: mostrar o que vem dando certo de forma a motivar.
- sensibilidade temporal: mostrar mudanças e tendências ao longo do tempo.

- definição de metas: permitir estabelecimento de metas a serem alcançadas.

- confiabilidade da fonte: possuir uma ou mais fontes de dados de confiança.

- capacidade de síntese: transmitir rapidamente uma informação, permitindo acesso aos detalhes, se necessário.

\section{Indicadores selecionados na escolha restrita}

Os indicadores operacionais encontrados na literatura foram agrupados segundo os princípios específicos mostrados anteriormente. Em seguida, foram selecionados aqueles que atenderam ao maior número de critérios, já estabelecidos. Este processo se deu, num primeiro momento, de forma restrita, com a participação de poucas pessoas envolvidas na pesquisa, a partir da análise da matriz (Tabela 1). Como resultado, foram escolhidos os indicadores constantes na Tabela 2 .

\section{Segunda etapa: escolha ampliada}

Formação do Grupo Jaboticabal Sustentável

O Grupo de Ação Jaboticabal Sustentável é formado por diversos setores 


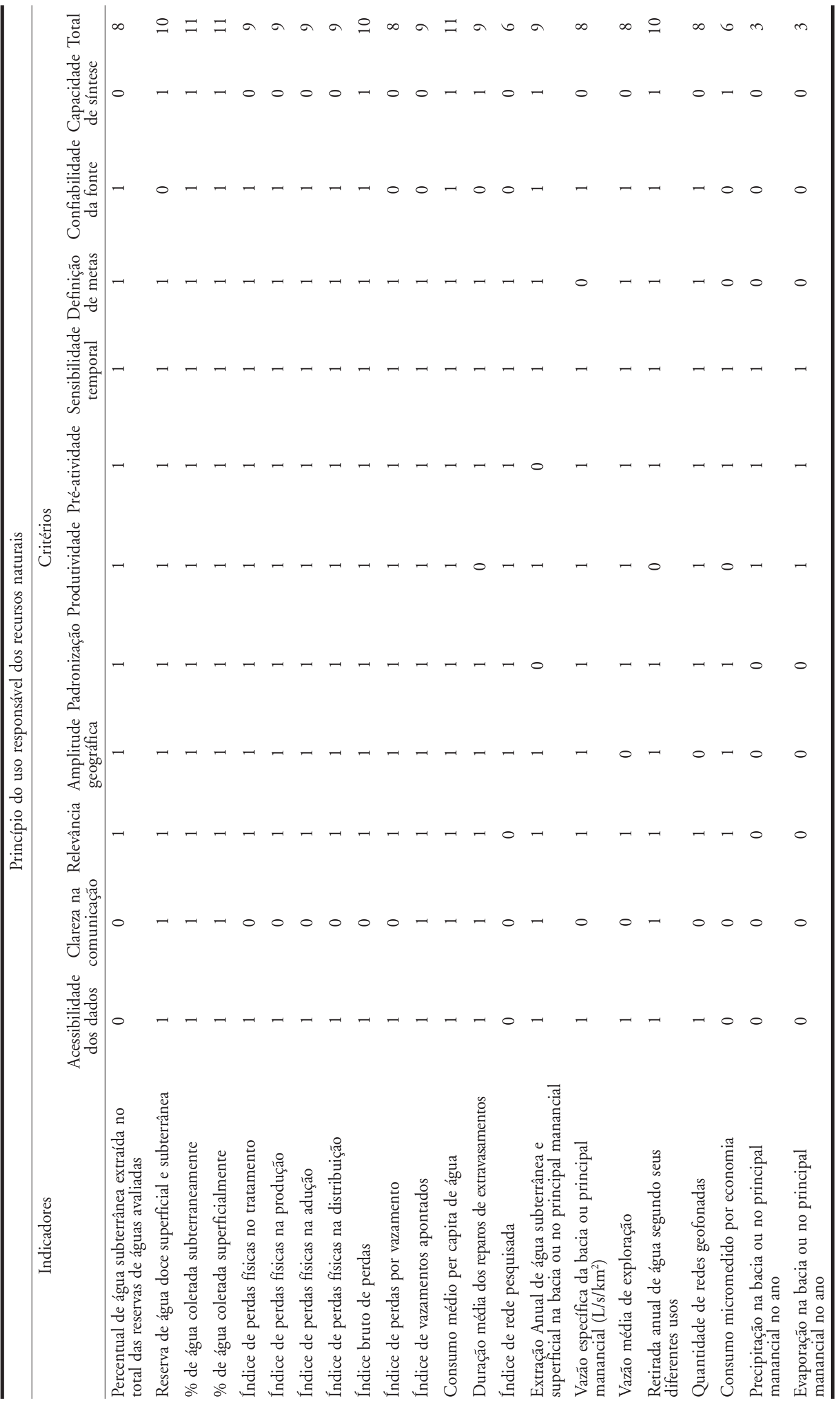


Tabela 2 - Indicadores da escolha restrita e sua proposta de avaliação

\begin{tabular}{|c|c|c|}
\hline $\begin{array}{l}\text { Princípio } \\
\text { específico }\end{array}$ & $\begin{array}{l}\text { Indicador } \\
\text { técnico }\end{array}$ & Avaliação da tendência \\
\hline \multirow[t]{3}{*}{ (1) Eqüidade } & $\begin{array}{l}\text { \% da pop. atendida por serviços } \\
\text { de abastecimento de água e } \\
\text { esgotamento sanitário }\end{array}$ & $\begin{array}{l}\text { - muito desfavorável: parte da população não é atendida por } \\
\text { nenhum dos sistemas, ou o atendimento de um deles é muito } \\
\text { baixo; } \\
\text { - desfavorável: parte da população não é atendida por um dos } \\
\text { sistemas; } \\
\text { - favorável: toda a população é atendida por abastecimento de água } \\
\text { e esgotamento sanitário. }\end{array}$ \\
\hline & $\begin{array}{l}\text { Número de interrupções no } \\
\text { sistema urbano de água e esgoto }\end{array}$ & $\begin{array}{l}\text { - muito desfavorável: interrupções freqüentes de abastecimento de } \\
\text { água ou esgotamento sanitário; } \\
\text { - desfavorável: interrupçóes, ainda que em pequeno número nos } \\
\text { sistemas de abastecimento de água e esgotamento sanitário; } \\
\text { · favorável: não existem interrupções nos sistemas de abastecimento } \\
\text { de água ou esgotamento sanitário, a não ser as previstas para } \\
\text { manutenção. }\end{array}$ \\
\hline & $\begin{array}{l}\text { Índice Geral de Qualidade de } \\
\text { Água (Teixeira, 1998) }\end{array}$ & $\begin{array}{l}\text { muito desfavorável: qualidade imprópria ou insatisfatória } \\
\text { (IGQA < 70); } \\
\text { - desfavorável: qualidade aceitável ou boa (IGQA entre } 70 \text { e 95); } \\
\text { - favorável: qualidade ótima ou excelente (IGQA > 95). }\end{array}$ \\
\hline $\begin{array}{l}\text { (2) Respeito às } \\
\text { condições locais }\end{array}$ & \multicolumn{2}{|c|}{$\begin{array}{l}\text { Não foi encontrado nenhum indicador apropriado, ficando definido que todos os indicadores propostos } \\
\text { em outros princípios devem respeitar as condiçōes locais (o que está presente, por exemplo, nos valores } \\
\text { de X e Y adotados como limites em alguns indicadores) }\end{array}$} \\
\hline $\begin{array}{l}\text { (3) Desempenho } \\
\text { econômico }\end{array}$ & $\begin{array}{l}\text { Volume de água produzida } \\
\text { por unidade monetária }\end{array}$ & $\begin{array}{l}\text { muito desfavorável: custos não identificados ou produção abaixo } \\
\text { de } \mathrm{X} \mathrm{m} \text { / / } \mathrm{R} \$ 1.000 ; \\
\text {. desfavorável: produção entre } \mathrm{X} \mathrm{m} \mathrm{m}^{3} \text { / } \mathrm{R} \$ 1.000 \text { e } \mathrm{Y} \mathrm{m} \mathrm{m}^{3} \text { / } \mathrm{R} \$ 1.000 \text {; } \\
\text {. favorável: produção acima de } \mathrm{Y} \mathrm{m} \mathrm{m}^{3} \text { / } \mathrm{R} \$ 1.000\end{array}$ \\
\hline $\begin{array}{l}\text { (4) Geração de } \\
\text { trabalho e renda }\end{array}$ & $\begin{array}{l}\text { Prioridade de investimentos } \\
\text { em atividades de melhoria, } \\
\text { gerando postos de trabalho }\end{array}$ & $\begin{array}{l}\text { - muito desfavorável: inexistência de investimentos e redução de } \\
\text { postos de trabalho; } \\
\text { - desfavorável: existência de investimentos mantendo o número de } \\
\text { trabalhadores, sem criar novos postos de trabalho; } \\
\text { - favorável: existência de investimentos com prioridade na geração } \\
\text { de novos postos de trabalho. }\end{array}$ \\
\hline $\begin{array}{l}\text { (5) Gestão } \\
\text { solidária e } \\
\text { participativa }\end{array}$ & $\begin{array}{l}\text { Existência de canais de } \\
\text { participação }\end{array}$ & $\begin{array}{l}\text { - muito desfavorável: inexistência de canais de participação relativos } \\
\text { aos sistemas urbanos de água e esgoto; } \\
\text { - desfavorável: existência de canais de participação, mas a população } \\
\text { não utiliza ou não sabe da existência; } \\
\text { - favorável: existência de canais de participação com a utilização } \\
\text { ativa por parte da população. }\end{array}$ \\
\hline
\end{tabular}


Tabela 2 - Indicadores da escolha restrita e sua propo (continuação)

\begin{tabular}{lcc} 
Princípio & Indicador & Avaliação da tendência \\
específico & técnico & \\
\hline
\end{tabular}

(6) Informação e sensibilização

(7) Uso responsável dos recursos naturais
Existência de informaçôes sistematizadas e disponibilizadas à população
- muito desfavorável: inexistência de informaçôes sistematizadas; - desfavorável: informaçōes sistematizadas, mas não são disponibilizadas à população; - favorável: as informaçōes são sistematizadas e divulgadas para a população.

Existência de formas de avaliação dos sistemas urbanos de água e esgoto pela população

Consumo de água per capita

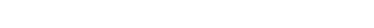

Indice de perdas no sistema

Existência de reuso e reaproveitamento de água pelos usuários

- muito desfavorável: o sistema não possui nenhuma forma de ser avaliado pela população;

- desfavorável: o sistema possui formas de avaliação dos serviços, mas não há um retorno por parte da população;

- favorável: o sistema possui formas de avaliação dos serviços pela população e há uma participação significativa.

- muito desfavorável: o consumo per capita é maior que a média $\mathrm{X} \mathrm{m}$ /hab.dia, estabelecida para este município; - desfavorável: o consumo per capita é praticamente igualado à média $\mathrm{X} \mathrm{m}^{3} / \mathrm{hab}$.dia, estabelecida para este município;

- favorável: o consumo per capita está abaixo da média X m3/hab.dia, e acima do mínimo Ym3/hab.dia, estabelecida para este município.

- muito desfavorável: o índice de perdas pelo sistema é superior à $\mathrm{X} \%$; a X\%;

- favorável: o índice de perdas é menor que Y\%.

- muito desfavorável: não existe qualquer forma de incentivo ao reuso ou reaproveitamento de água pelos usuários;

- desfavorável: existe alguma forma de incentivo ao reuso ou
- desfavorável: o índice de perdas pelo sistema se encontra entre Y\% reaproveitamento de água pelos usuários, mas com resultados pouco significativos;

- favorável: o reuso ou o reaproveitamento de água pelos usuários são incentivados e ocorrem de forma significativa.

Consumo de energia elétrica pelo sistema, por $\mathrm{m}^{3}$ de água produzida

(8) Prevenção e compensação de IQA - Índice de Qualidade da Água, medido a montante e a jusante do município
- muito desfavorável: o consumo de energia elétrica pelo sistema é superior a X KWh $/ \mathrm{m}^{3}$ água produzida;

- desfavorável: o consumo de energia elétrica pelo sistema fica entre $\mathrm{X} \mathrm{KWh} / \mathrm{m}^{3}$ água produzida e $\mathrm{Y} \mathrm{KWh} / \mathrm{m}^{3}$ água produzida;

- favorável: o consumo de energia elétrica pelo sistema é inferior a $Y$ $\mathrm{KWh} / \mathrm{m}^{3}$ água produzida.

- muito desfavorável: qualidade da água ruim ou péssima (IQA < 36);

- desfavorável: qualidade aceitável ou boa (IQA entre 37 e 79);

- favorável: qualidade ótima (IQA > 80). 
da sociedade, incluindo os serviços municipais, a administração pública, organizaçôes não governamentais, universidades e sociedade civil.

Para a formação deste Grupo, a Universidade Federal de São Carlos em parceria com a Prefeitura Municipal de Jaboticabal, por meio do projeto "Incorporação de Princípios e Indicadores de Sustentabilidade na Formulação de Políticas Urbanas em Pequenos e Médios Municípios" (Teixeira, 1999), convidou representantes das diferentes instituições a participarem e formarem um Grupo de Ação para a escolha e o monitoramento de diferentes indicadores para a avaliação da sustentabilidade no município.

O início das atividades deste Grupo ocorreu em 1999, com a implantação do projeto citado anteriormente no município, e vem se consolidando e ampliando ao longo dos anos.

Como primeiro trabalho realizado junto a este Grupo, foram discutidos e definidos conceitos de sustentabilidade e de indicadores, que resultou em uma publicação direcionada à população local. Nela, foram definidos os conceitos de sustentabilidade, bem como suas dimensões, além da importância da utilização de indicadores para o monitoramento, resultado de uma oficina de trabalho e discussões com o Grupo.

Em seguida, a definição de indicadores para o monitoramento das diversas políticas aplicadas ao município se torna etapa seguinte deste projeto a ser desenvolvida por este Grupo. Para isso, o tema "Água" foi escolhido como o primeiro a definir indicadores que possam ser monitorados pela população, e assim monitorar as políticas públicas aplicadas no município.

\section{Dimensões de sustentabilidade}

Por meio de oficinas de trabalho e discussão realizadas junto ao município de Jaboticabal e ao Grupo de Ação Jaboticabal Sustentável, foram definidas as dimensões de sustentabilidade que devem ser incorporadas nos diferentes setores do município, como pode ser observado a seguir:

- Dimensão Ambiental: garantir que a utilização dos recursos naturais não comprometa a qualidade ambiental;

- Dimensão Econômica: gerar oportunidades de trabalho e emprego, favorecendo uma distribuição mais equilibrada dos benefícios econômicos;
- Dimensão Social: garantir que todas as pessoas tenham condiçôes iguais de acesso a bens e serviços de boa qualidade, necessários para uma vida digna;

- Dimensão Cultural: promover, preservar e divulgar a história, tradiçōes e valores regionais, acompanhando suas transformaçôes;

- Dimensão Política: garantir a participação efetiva e organizada da população nos processos de planejamento, execução e fiscalização de projetos que beneficiem a maioria das pessoas, promovendo a cidadania ativa.

Com a definição das dimensões, os indicadores são adequados a elas segundo suas características, permitindo que todas as vertentes possam ser monitoradas.

\section{Critérios para a escolha de indicadores}

Após a definição das dimensões, a próxima etapa foi a definição de critérios para a escolha de indicadores que pudessem apresentar informaçóes relevantes aos usuários e à administração. A partir de critérios referenciados pela literatura, $\mathrm{o}$ Grupo de Ação estabeleceu cinco critérios, estabelecidos a partir da aglutinação e adaptação de alguns deles, sendo:

- Representatividade: foi estabelecido através do critério de "Relevância", que foi adequado para que se tornasse representativo para os usuários. Neste caso, este critério seria de exclusão, ou seja, se o indicador não for representativo a seus usuários, ele não será analisado por nenhum outro critério, ficando temporariamente excluído da lista de monitoramento.

- Comparabilidade: foi estabelecido a partir dos critérios "Amplitude Geográfica" e "Sensibilidade Temporal". Neste critério fica estabelecido que o indicador deve ser comparável tanto no espaço (diferentes locais: cidades, bairros, países, etc) como no tempo (durante um certo período: anos, meses, etc).

- Coleta de Dados: surge a partir dos critérios "Acessibilidade dos Dados", "Padronização", "Confiabilidade da Fonte" e "Custo da Coleta". Neste caso, a coleta de dados deve ser de fácil acesso, sem custos excessivos, mas prevendo que a fonte dos dados seja confiável. Para isso, quanto mais padronizado for o indicador, mais fácil para encontrar seus dados e assim também, a facilidade na comparação dos mesmos.

- Clareza e Síntese: envolve os seguintes critérios "Clareza na Comunica- ção" e "Capacidade de Síntese". Neste caso, o indicador deve ser claro para os seus usuários, transmitindo a informação de maneira simples e compreensível, e ter a capacidade de sintetizar informaçóes em um único indicador.

- Previsão e Metas: estabelecido a partir de "Preditividade", "Pró-Atividade" e "Definição de Metas". Assim, o indicador deve fornecer previsões dos problemas que possam acontecer, mostrar as evoluções motivando a população e definir metas de melhoria.

A partir disso, os indicadores préselecionados passaram por uma avaliação, proposta por meio de uma matriz, que atribuía pesos aos indicadores como: (0) o indicador não atende ao critério; (1) o indicador atende pouco ao critério; (2) o indicador atende plenamente ao critério.

\section{Indicadores selecionados na escolha ampliada}

Após a análise pela matriz (Tabela 3), os indicadores pontuados foram adequados às dimensões de sustentabilidade para identificar lacunas que pudessem ocorrer caso uma delas não fosse contemplada com nenhum indicador. Com isso, as dimensões atribuídas a cada indicador selecionado podem ser observadas no Tabela 4.

\section{CONCLUSÕES}

O estabelecimento de princípios específicos e de indicadores de sustentabilidade para os SAA e SES pode colaborar na elaboração e implantação de políticas públicas (definição de investimentos, desenvolvimento de campanhas de mobilização etc), bem como monitorar as açōes realizadas.

Apesar da utilização de métodos de escolha diferentes, pode-se perceber que alguns indicadores foram coincidentes ou mediam a mesma variável, o que mostra a mesma tendência em analisar os problemas relacionados aos sistemas urbanos de água e esgoto, como pode ser observado no Tabela 5.

A análise de indicadores como forma de monitoramento de políticas públicas, portanto, resultou em um conjunto de indicadores bastante satisfatório, podendo abranger as diversas dimensões, mostrando sua tendência à sustentabilidade. 
Tabela 3 - Matriz para a escolha ampliada dos indicadores de sustentabilidade para os SAA e SES de Jaboticabal/SP

\begin{tabular}{|c|c|c|c|c|c|c|}
\hline Indicadores & Representatividade & Comparabilidade & $\begin{array}{l}\text { Coleta de } \\
\text { dados }\end{array}$ & $\begin{array}{l}\text { Clareza e } \\
\text { síntese }\end{array}$ & $\begin{array}{l}\text { Previsão } \\
\text { e metas }\end{array}$ & Total \\
\hline $\begin{array}{l}\text { Número de campanhas educacionais } \\
\text { ligadas à água }\end{array}$ & 0 & & & & & 0 \\
\hline Consumo de água por habitante & 2 & 2 & 2 & 2 & 2 & 10 \\
\hline Perdas de água no sistema de água & 2 & 2 & 1 & 1 & 2 & 8 \\
\hline $\begin{array}{l}\text { Número de pontos de lançamento } \\
\text { de esgotos nấo tratado em corpos } \\
\text { d'água }\end{array}$ & 2 & 2 & 1 & 2 & 2 & 9 \\
\hline $\begin{array}{l}\text { Número de ligações de água pluvial } \\
\text { em rede de esgoto, causando retorno }\end{array}$ & 0 & & & & & 0 \\
\hline $\begin{array}{l}\text { Presença de caixa de retençãao de } \\
\text { gordura nas residências }\end{array}$ & 0 & & & & & 0 \\
\hline $\begin{array}{l}\text { Percentual de reutilização de água } \\
\text { residuária em residências }\end{array}$ & 0 & & & & & 0 \\
\hline $\begin{array}{l}\text { Percentual de residências com falta } \\
\text { de água }\end{array}$ & 2 & 2 & 2 & 2 & 2 & 10 \\
\hline $\begin{array}{l}\text { Número de casos de doenças por } \\
\text { veiculação hídrica }\end{array}$ & 1 & 1 & 1 & 1 & 2 & 6 \\
\hline $\begin{array}{l}\text { Número de vazamentos de esgoto na } \\
\text { rede coletora }\end{array}$ & 2 & 0 & 0 & 1 & 1 & 4 \\
\hline Número de poços artesianos & 0 & & & & & 0 \\
\hline Vazão dos rios para a captação & 2 & 2 & 2 & 2 & 2 & 10 \\
\hline $\begin{array}{l}\text { Freqüência de limpeza de caixa } \\
\text { d'água }\end{array}$ & 2 & 2 & 0 & 2 & 1 & 7 \\
\hline $\begin{array}{l}\text { Número de trabalhadores que } \\
\text { limpam caixas d'água }\end{array}$ & 0 & & & & & 0 \\
\hline
\end{tabular}


Tabela 4 - Indicadores da escolha ampliada e sua proposta de avaliação

\begin{tabular}{|c|c|}
\hline Indicador & Proposta de Avaliação \\
\hline Consumo de água per capita & 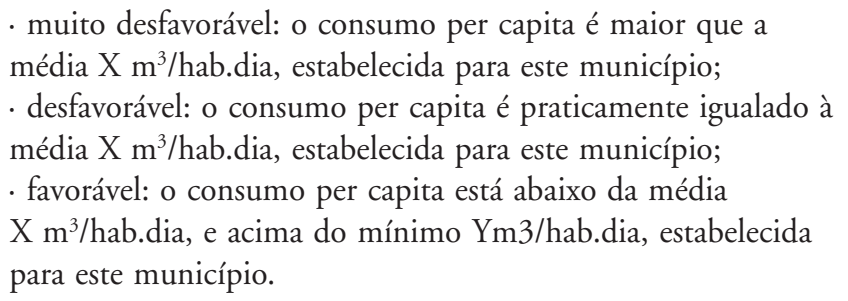 \\
\hline $\begin{array}{l}\text { Número de reclamações de falta de } \\
\text { água nas residências }\end{array}$ & $\begin{array}{l}\text { muito desfavorável: existe um número significativo de } \\
\text { reclamações de falta de água nas residências; } \\
\text { desfavorável: existem, ainda que em pequeno número, } \\
\text { reclamações de falta de água nas residências; } \\
\text { - favorável: não existem reclamaçóes de falta de água } \\
\text { nas residências. }\end{array}$ \\
\hline Vazão dos rios para a captação & $\begin{array}{l}\text { - muito desfavorável: as vazões de todos os mananciais vêm } \\
\text { diminuindo ao longo do tempo; } \\
\text { · desfavorável: a vazão de algum dos mananciais vem } \\
\text { diminuindo ao longo do tempo; } \\
\text { · favorável: as vazões dos mananciais sofrem apenas reduções } \\
\text { sazonais, nos períodos de seca, sem uma tendência de } \\
\text { diminuição constante. }\end{array}$ \\
\hline $\begin{array}{l}\text { Número de pontos de lançamento } \\
\text { de esgoto "in natura" nos } \\
\text { corpos d'água }\end{array}$ & $\begin{array}{l}\text { - muito desfavorável: existem diversos pontos de lançamento de } \\
\text { esgoto, sem nenhum tratamento, ou poucos pontos, mas com } \\
\text { grande carga poluidora; } \\
\text { - desfavorável: existem poucos pontos com lançamento de } \\
\text { esgoto, e sua carga poluidora não é significativa; } \\
\text { - favorável: não existem pontos de lançamento de } \\
\text { esgoto "in natura". }\end{array}$ \\
\hline $\begin{array}{l}\text { Índice de perdas de água } \\
\text { no sistema }\end{array}$ & $\begin{array}{l}\text { - muito desfavorável: o índice de perdas pelo sistema é superior } \\
\text { a X\%; } \\
\text { - desfavorável: o índice de perdas pelo sistema se encontra entre } \\
\text { Y\% a X\%; } \\
\text { - favorável: o índice de perdas pelo sistema é menor que Y\%. }\end{array}$ \\
\hline $\begin{array}{c}\text { Freqüência de limpeza de caixas } \\
\text { d'água residenciais }\end{array}$ & $\begin{array}{l}\text { - muito desfavorável: os moradores nunca limpam } \\
\text { sua caixa d'água; } \\
\text { - desfavorável: os moradores não limpam sua caixa d'água } \\
\text { com freqüência; } \\
\text { · favorável: os moradores limpam freqüentemente sua caixa } \\
\text { d'água, pelo menos duas vezes ao ano. }\end{array}$ \\
\hline
\end{tabular}


Tabela 4 - Indicadores da escolha ampliada e sua proposta de avaliação (continuação)

\begin{tabular}{|c|c|}
\hline Indicador & Proposta de Avaliação \\
\hline Número de vazamentos de esgoto & $\begin{array}{l}\text { muito desfavorável: existe um grande } \mathrm{n}^{\circ} \text { de ocorrências de } \\
\text { vazamentos de esgoto detectadas } \\
\text { - desfavorável: existe um } n^{\circ} \text { pequeno, mas significativo de } \\
\text { ocorrências de vazamento de esgoto } \\
\text { - favorável: existe um } n^{\circ} \text { insignificante de ocorrências de } \\
\text { vazamento de esgoto. }\end{array}$ \\
\hline $\begin{array}{l}\text { Número de casos de doenças de } \\
\text { veiculação hídrica }\end{array}$ & $\begin{array}{l}\text { - muito desfavorável: existe um número muito grande da } \\
\text { população sofrendo de doenças de veiculação hídrica, } \\
\text { inclusive causando óbitos; } \\
\text { · desfavorável: existe um número pequeno de casos de doenças } \\
\text { de veiculação hídrica, mas ainda significativo; } \\
\text { · favorável: não existem casos de doenças de veiculação } \\
\text { hídrica no município. }\end{array}$ \\
\hline $\begin{array}{l}\text { Existência de conselho de gestão de } \\
\text { recursos hídricos }\end{array}$ & $\begin{array}{l}\text { - muito desfavorável: não existe nenhum conselho relacionado } \\
\text { aos recursos hídricos; } \\
\text { - desfavorável: existe conselho relacionado aos recursos hídricos, } \\
\text { porém com pouca atuação ou sem acesso da população; } \\
\text { · favorável: existe conselho relacionado aos recursos hídricos, } \\
\text { atuante e com acesso da população. }\end{array}$ \\
\hline $\begin{array}{l}\text { Desconformidades da água segundo } \\
\text { os padróes de potabilidade }\end{array}$ & $\begin{array}{l}\text { - muito desfavorável: as análises estão freqüentemente } \\
\text { desconformes com o padrão de potabilidade; } \\
\text { - desfavorável: poucas análises estão desconformes com o } \\
\text { padrão de potabilidade; } \\
\text { · favorável: as análises atendem às exigências do padrão } \\
\text { de potabilidade. }\end{array}$ \\
\hline $\begin{array}{l}\text { Desconformidades com o } \\
\text { enquadramento dos corpos hídricos }\end{array}$ & $\begin{array}{l}\text { - muito desfavorável: as análises estão freqüentemente } \\
\text { desconformes com o enquadramento dos corpos hídricos; } \\
\text { - desfavorável: poucas análises estão desconformes com o } \\
\text { enquadramento dos corpos hídricos; } \\
\text { · favorável: as análises estão freqüentemente dentro do } \\
\text { enquadramento dos corpos hídricos estabelecidos. }\end{array}$ \\
\hline $\begin{array}{l}\text { Quantidade de produto químico } \\
\text { utilizado no tratamento } / 1000 \mathrm{~m}^{3} \mathrm{de} \\
\text { água tratada }\end{array}$ & $\begin{array}{l}\text { - muito desfavorável: a quantidade de produtos químicos } \\
\text { utilizados no tratamento de } 1000 \mathrm{~m}^{3} \text { de água } \\
\text { aumenta freqüentemente; } \\
\text { - desfavorável: a quantidade de produtos químicos utilizados no } \\
\text { tratamento de } 1000 \mathrm{~m}^{3} \text { de água se mantém estável; } \\
\text { - favorável: a quantidade de produtos químicos utilizados no } \\
\text { tratamento de } 1000 \mathrm{~m}^{3} \text { de água está diminuindo. }\end{array}$ \\
\hline $\begin{array}{l}\text { Abordagem do tema água no ensino } \\
\text { de forma ampla }\end{array}$ & $\begin{array}{l}\text { - muito desfavorável: não existe qualquer forma de abordagem } \\
\text { do tema água em nenhuma forma de ensino; } \\
\text { - desfavorável: existe a abordagem do tema água apenas em } \\
\text { escolas de primeiro e segundo grau; } \\
\text { · favorável: existe a abordagem do tema água de forma ampla, } \\
\text { contemplando toda a população. }\end{array}$ \\
\hline
\end{tabular}


Tabela 5 - Análise comparativa de indicadores na escolha restrita e na escolha ampliada

\begin{tabular}{cc}
\hline Escolha Restrita & Escolha Ampliada \\
\hline Consumo de água per capita & Consumo de água per capita \\
Índice de perdas no sistema & Índice de perdas no sistema \\
Interrupções no sistema & Falta de água nas residências \\
Índice Geral de Qualidade da & Desconformidades com o padrão \\
Água - IGQA & de potabilidade \\
Índice de Qualidade da Água - & Desconformidades com o enquadramento \\
IQA & dos corpos hídricos
\end{tabular}

\section{REFERÊNCIAS}

BOSSEL, H. Indicators for sustainable developmet: theory, method, applications - a report to the Balaton Group. Manitoba: International Institute for Sustainable Development, 1999.

CAVALCANTI, C. (org) Meio ambiente, desenvolvimento sustentável e politicas públicas. São Paulo: Cortez: Recife: Fundação Joaquim Nabuco, 2a. edição, 1999.

COMISSÃO MUNDIAL SOBRE MEIO AMBIENTE E DESENVOLVIMENTO (CMMAD) - Nosso Futuro Comum. Ed. Fundação Getúlio Vargas - Rio de Janeiro, 1991.

KAYANO, J. \& CALDAS, E. L. Indicadores para o diálogo. In: CACCIA-BAVA, S. (coord.) Novos contornos da gestão local: conceitos em construção. São Paulo: Polis, 2002.

LUNDIN, M. Assessment of the environmental sustainability of urban water systems, Chalmers University of Technology. Göteborg, Sweden, 1999.

MILANEZ, B. Resíduos Sólidos $e$ Sustentabilidade: Principios, Indicadores e Instrumentos de Ação. Dissertação de Mestrado PPGEU/UFSCar - São Carlos, 2002.
MIRANDA, A.B.; TEIXEIRA, B.A.N. Princípios Especificos de Sustentabilidade para Sistemas Urbanos de Abastecimento de Água e Esgotamento Sanitário ECOURBS, Florianópolis, 2002.

SILVA, S. R. M. Indicadores de sustentabilidade urbana: as perpectivas $e$ as limitaçôes da operacionalização de um referencial sustentável. Dissertação de Mestrado em Engenharia Urbana. São Carlos: UFSCar. 2000.

SUSTAINABLE SEATTLE. Indicators of sustainable community: a status report on log term cultural, economic and environmental health of Seattle/King County. Seattle, 1998.

TEIXEIRA, B. A. N. (coord.). Incorporaçôes dos principios e indicadores de sustentabilidade na formulação de políticas urbanas em pequenos $e$ médios municípios. Projeto aprovado no Programa de Pesquisa em Políticas Públicas da FAPESP, Edital 1. São Carlos, 1999.

TEIXEIRA, B. A. N.; SILVA, R. S. (coords.) Urbanismo e saneamento urbano sustentáveis. Segundo Relatório. São Carlos, 1998.

TEIXEIRA, B. A. N.; SALVADOR, N. B. N.; CORDEIRO, J. S. Estudos para a padronização de um indice de qualidade de água para a SABESP. Relatório no 4 - Contrato 060/97. Sabesp. São Carlos, 1998.

\section{Endereço para correspondência:}

Aline Branco de Miranda Rua Castro Alves, 299 - Centro 14870-000 Jaboticabal - SP - Brasil Tel: (16) 3202-220I

E-mail: alinebmiranda@yahoo.com.br

\title{
LOJA DE LIVROS ESPECIALIZADA EM SANEAMENTO E MEIO AMBIENTE
} ABES

\author{
livraria@abes-dn.org.br \\ www.abes-dn.org.br
}

